early in 1982. You can count on me to join in efforts to provide adequate funding for the ICA's cultural and academic programs.

I appreciated having your input on this issue.

Sincerely,

Alan Cranston

United States Senate

\title{
Annual Award for Life-Long Contribution to African Studies
}

Dear Don,

Every year the Association honors the author of the most outstanding work on Africa in its Herskovits award. The award is prestigious and has gained in status over the years. I think however that an Association like our own, rapidly approaching its silver jubilee in 1982, should institute an even more prestigious award for life-long service to African Studies. Such life-long career awards are a feature of many long established associations in individual disciplines, particularly in Europe where special medals are struck to honor the recipient. Many of these awards are named after outstanding scholars so that the distinction is a shared one between the recipient and the person after whom the award is named. Many of our leading Africanists never receive the Herskovits award and as a consequence are never honored for the work they do by our Association. A feature of many of our distinguished Africanists is their interdisciplinary breadth of vision and expertise, a valuable asset in an Africanist but not necessarily a credential to assure them adequate recognition in their parent discipline.

I should like to recommend to the Governing Board of the Association that an annual award be instituted whereby we recognize life-long achievement. The recipients would not necessarily have to be academics. Nominees could also include journalists, diplomats, economic advisers, scientists or anyone we might deem as a collective body to have made a significant contribution to the African cause and particularly to the promotion of African scholarship, education; to a greater understanding of Africa within the English-speaking world; or to the improvement of the quality of life, interpreted in its widest sense, in Africa. What I have in mind is something similar to the award scheme at one time initiated by the Haile Selassie Foundation which honored scholars of the ilk of Louis Leakey and Theodore Monod.

Nominations would be reviewed by a standing committee of the Association which would include on it a significant number of persons with at least 15 years experience in African studies. Assessors would also be invited from amongst our distinguished colleagues in Africa who could evaluate the impact and influence of the work of the nominees within Africa itself. In the first instance, whilst the endowment might be limited and administrative snags not ironed out, the award should be limited to scholars residing or working presently or for a significant part of their career in North America. Each recipient would be honored at a special dinner which would be held during the annual meeting of the Association and at which the Association would be informed of the achievements of the honoree who would then deliver a specially prepared address. The address and the introduction would be printed in either one of the Association's journals or preferably in a specially produced booklet. Carefully selected guests, including diplomats, key journalists and State Department employees would be invited to the dinner to add further honor to the occasion.

It would be appropriate to give a name to the award such as the Africa medal or it could be named after a deceased Africanist scholar of distinction such as W.B. Du Bois or anyone else who met the approbation of the Board. The award should consist of a specially struck medallion and ribbon (or some similar physical memento of intrinsic value) 
and if possible a small cash award of a value equivalent at least to the Herskovits award. To establish such an award we would need an endowment of at least $\$ 50,000$ which could yield (depending on interest rates) a minimum of $\$ 4-5000$ p.a. to pay for the fare and accommodation of the recipient and spouse, the cost of the award, the publication of the booklet and the invitations to special guests to attend the dinner. If a sufficient endowment was secured the cash award could be made the equivalent of not more than $10 \%$ (or any percentage agreed by the Board) of the annual income of the endowment. Any excess funds could be used to provide bursaries to graduates to attend the A.S.A. meeting, such bursaries would bear the same name as the award and would themselves be of a com. petitive nature. All ex-recipients of the award would be invited to participate in the future selection process. I have in mind that the award ceremony would be an occasion for the Association to celebrate in the achievements of our greatest scholars. I feel that the presentation of the Herskovits award leaves much to be desired often taking place at a hurried and often poorly attended General meeting. I should like to think that the new award dinner ceremony and the address by the recipient and the recital of their exploits would be an inspiration to the young Africanists who are just beginning their exciting careers.

The above thoughts are only intended as suggestions, detailed in order to elicit discussion, for the Board to consider. If the idea has any merit I feel that it would be appropriate to launch the award scheme in the Jubilee year when we meet in the nation's capital and during which time an appeal to the interested public might meet with a kinder response.

\author{
Yours Sincerely, \\ Merrick Posnansky \\ Professor of History and Anthropology
}

Ed note: Professor Posnansky is a member of this year's Herskovits Committee, along with Professors Lindfors and Samoff (Chair)

\title{
OVERSEAS MAIL PROBLEMS
}

\section{Dear Executive Secretary:}

Your cancellation last August of my Sustaining Membership of A.S.A did not take into account the long weeks which it takes sea-mailed A.S.A. mail to reach me-an experience which I feel sure other members in this part of the world share. To illustrate, the final dues-payment reminder posted in April 1981 reached me in August, the cancellation notice arrived in October and copies of each A.S.A. periodical came to me several months after their publication; the December 1980 (Volume XXIII NO3) REVIEW reached my hands just last week!

It is important that A.S.A. members in this part of the world should receive all A.S.A. materials and mail promptly and I, for myself, am willing to pay a little more than the normal dues to help ensure this. Please let me have your reactions soonest. Meanwhile I enclose $\$ 30$ cheque for my 1982 due.

\author{
Yours Sincerely \\ Professor O. (A Member from Nigeria)
}

\section{Dear Professor O:}

Thank you very much for your prompt payment of your 1982 dues. Your sustaining membership is hereby reinstated.

Your comments concerning the shipment of ASA membership information by surface are well taken. We have tried to rectify that situation this year, as your renewal notice testifies. However, as to the shipment of membership journals, those will continue to be 